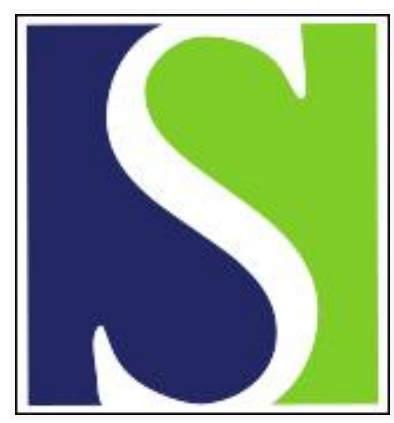

Scand J Work Environ Health 2021;47(4):268-276

https://doi.org/10.5271/sjweh.3952

Published online: 23 Mar 2021, Issue date: 01 May 2021

The associations of working hour characteristics with short sickness absence among part- and full-time retail workers

by Shiri R, Hakola T, Härmä M, Ropponen A

The present study suggests that percent and number of short $(<11$ hours) shift intervals strongly predict short sickness absence among retail workers with a dose-response relationship. Weekly working hours $>40$ hours and night shift also predict short sickness absence among retail workers.

Affiliation: Finnish Institute of Occupational Health, PO Box 18, FI-00032 Työterveyslaitos, Helsinki. rahman.shiri@ttl.fi

Refers to the following text of the Journal: 2015;41(3):268-279

The following article refers to this text: 2023;49(2):117-125

Key terms: night shift; quick return; retail worker; risk factor; shift work schedule; sick leave; sickness absence; working hour characteristic

This article in PubMed: www.ncbi.nlm.nih.gov/pubmed/33755187 


\title{
The associations of working hour characteristics with short sickness absence among part- and full-time retail workers
}

\author{
by Rahman Shiri, MD, PhD, ${ }^{1}$ Tarja Hakola, MSc, ${ }^{1}$ Mikko Härmä, MD, PhD, ${ }^{1}$ Annina Ropponen, PhD ${ }^{1}$
}

\begin{abstract}
Shiri R, Hakola T, Härmä M, Ropponen A. The associations of working hour characteristics with short sickness absence among part- and full-time retail workers. Scand J Work Environ Health. 2021;47(4):268-276. doi:10.5271/sjweh.3952
\end{abstract}

Objective This study aimed to determine the associations of working hour characteristics with short (1-3 days) sickness absence (SA) among retail workers.

Methods As part of "RetailHours-project", 4046 employees of 338 Finnish retail stores were included. Registrybased data on working hour characteristics and short SA were utilized. A case-crossover design was used and the odds ratios (OR) were controlled for the clustering effect and working hour characteristics.

Results There were strong dose-response relationships between percent of short ( $<11$ hours) shift intervals and short SA among part- and full-time workers, men and women, and younger and older workers. Compared to workers without short shift intervals, the risk of SA was 1.47 times [95\% confidence interval (CI) 1.29-1.68] higher among workers who had short shift intervals $\leq 10 \%$ of work times, 2.39 times (95\% CI 2.03-2.82) higher among workers who had $10-25 \%$ of work times, and 4.03 times (CI 2.34-6.93) higher among workers who had short shift intervals $>25 \%$ of work times. Weekly working hours $>40$ hours were associated with SA among part-time workers [odds ratio (OR) 2.22, CI 1.65-2.98], women (OR 1.62, CI 1.27-2.07) and among workers $<30$ years of age (OR 1.68, CI 1.20-2.35) as well as among workers aged $\geq 30$ years (OR 1.43, CI 1.07-1.92). Furthermore, working mainly night shifts was associated with SA among full-time workers (OR 2.41, 95\% CI 0.99-5.86) and women (OR 1.72, CI 1.02-2.89).

Conclusions A short shift interval is an important risk factor for short SA. Improving intervals between shifts and shortening long weekly working hours could reduce the risk of short SA among retail workers.

Key terms night shift; quick return; risk factor; shift work schedule; sick leave.

Sickness absence (SA) is commonly used as an indicator for monitoring work-related health (1). Prospective cohort studies found an association between shift work and SA $(2,3)$. A systematic review of studies published up to April 2010 found an association between fixed evening shifts and SA among female healthcare workers but showed inconclusive evidence for rotating and night shifts (4). Since then, studies utilizing register-based data among hospital workers showed that long weekly working hours (5), long shifts ( $\geq 12$ hours) $(6,7)$, night shifts $(3,5), 2-$ and 3 -shift rotations (3), and short $(<11$ hours) interval between shifts $(5,8)$ increased the risk of short SA. Shift work that included night work also increased the risk of short SA among female-dominated occupations (2). Furthermore, lack of influence on working hours (9), evening work (10), night shift work (10,
11), 3-shift schedule (12), and shifts that lasted $\geq 12$ hours (6) increased the risk of long-term SA.

Retail grocery stores and supermarkets provide vital services to the communities. Retail workers are exposed to physical workload factors such as forceful lifting, forceful pushing, pulling or carrying heavy loads, repetitive movements of the hands or wrists, working with arms above the shoulder level, and awkward and static postures (13-15). As a consequence, retail workers are at increased risk of developing musculoskeletal disorders such as neck or shoulder disorders, back disorders, tendinitis, and carpal tunnel syndrome (13-18). Around half of women working at grocery stores reported neck or shoulder complaint in the preceding 7 days and $34 \%$ reported elbow or hand complaints (17). Since musculoskeletal disorders, particularly back and shoulder disor-

1 Finnish Institute of Occupational Health, Helsinki, Finland,

Correspondence to: Rahman Shiri, Finnish Institute of Occupational Health, PO Box 18, FI-00032 Työterveyslaitos, Helsinki. [E-mail: rahman.shiri@ttl.fi] 
ders, are common causes of SA (19), retail workers are at risk of SA. Retail workers are also exposed to psychosocial risk factors such as high job strain $(14,17,20)$. An earlier study showed that the association between night shift work and short SA among female-dominated occupations is not due to differences in psychosocial factors between day and night shift workers (2).

To date, little is known about the effects of occupational risk factors on musculoskeletal disorders and their associated disability among grocery store workers (18). Of these workers, only cashiers have mostly been studied $(14,15,21)$. Among retail grocery store workers, work schedules more often are unpredictable and unstable, and most workers have little control over their shift work schedules (22). Grocery store workers with unstable and unpredictable work schedules reported poorer sleep quality, had more difficulty in falling asleep, woke more frequently during sleep, and felt tired more often than workers with more stable and predictable work schedules (22). To our knowledge, to date, no study has identified the predictors of SA related to working hour characteristics among retail workers. Similar to healthcare workers, retail workers are predominantly women $(5,22)$, however, they are somewhat younger and more often work as a part-time job than healthcare workers $(5,22)$. Furthermore, it is unclear whether age, sex, or type of work contact (part-time or full-time) play a role in the associations between working hour characteristics and short SA. Some previous studies found an increased risk of SA only among older shift workers (10) or among older employees working $>40$ hours/week (23). Also, a study showed that part-time workers are at higher risk of SA than full-time workers (24).

The aim of the present study was to explore the associations of working hour characteristics with short (1-3 days) SA among retail workers. Moreover, we determined whether the associations differ between partand full-time workers, men and women, and younger and older workers.

\section{Methods}

\section{Population}

Data were gathered as part of the development of working hours in retail project ("RetailHours-project") that consists of three regions in a chain of companies in the retail sector in Finland. The regions were the capital area of Finland ( $>11000$ employees), Middle Finland ( $>2700)$ and Northeast Finland $(\mathrm{N}>2200)$. In total, in this chain of companies, there were 900 outlets across Finland and the RetailHours-project included 450 (50\%) of them. The RetailHours-project had in total working hour data from 16728 employees from 6 March 2017 to 31 December 2019. We selected the final sample to include only those who were employed by the three regions (ie, we excluded the agency workers who were employed by other companies and paid on an hourly basis, $\mathrm{N}=1411$ ) and those who did not have working hours according to the collective agreement of sales sector ( $\mathrm{N}=3864$ being employees of other service sectors such as hospitality). Furthermore, the population of the current study was restricted to employees who had at $\geq 1$ short (1-3 days) SA (ie, the first incidence of short SA since 6 March 2017) and had data on working hour characteristics during eight weeks before the first short SA (N=4046, 911 men and 3083 women). Since the data comprised employer-owned employment information without access to diagnosis-specific SA, no ethical approval was required for the study.

\section{Outcome}

We used 1-3 SA days as the outcome of the study. In Finland and the other Nordic countries, a SA of $\leq 3$ days does not need a medical certificate. For each participant, data on starting and ending SA was collected.

\section{Characteristics of working hours}

Data on the working hour characteristics during eight weeks before SA were collected. The payroll-based employer's owned registry data of daily working hours were retrieved from the shift scheduling program Ortec Workforce Scheduling (Elli)-program. Information on the number of weekly working hours, type of shift (early morning, morning, day, evening, and night), length of work shift, and percentage and number of short $(<11$ hours) shift intervals (interval between two consecutive work shifts) was collected. Also, data included information on age, sex, and part-time and full-time work based on the employment contract. The data did not contain reasons for part-time work (ie, if part-time work was due to health, childcare, studies or else).

For each participant, data included information on starting and ending of each work shift. We defined day shift as a shift of $\geq 3$ hours between 08:00 and 18:00 hours, morning shift as a shift between 03:00 and 18:00 hours, evening shift as a shift between 18:00 and 23:00 hours, and night shift as a shift between 23:00 and 06:00 hours as modified from Larsen et al (10) and Härmä et al (25-26) for retail work. An early morning shift starts before 06:00 hours and is not classified as a night shift. The classification of the timing of the shift was not mutually exclusive, but we gave highest priority to the night shifts, the second highest to the evening shifts and the lowest priority to the day shifts (26). Early morning and morning shifts did not overlap with 
other shifts. To distinguish different shifts, we defined a particular shift (eg, night shift) as working $\geq 50 \%$ of the work time during four weeks in that shift, and those who worked $<50 \%$ of the time in a particular shift were group in a separate category of any shift $<50 \%$. Day shift has the lowest health risk (26), however, due to a small number of day workers in the current study, we compared night, evening, early morning and day shifts with morning shift. We also classified the length of shifts into short ( $<4$ hours), medium (4-9 hours) and long ( $>9$ hours). We defined a short interval between two shifts (quick return) as an interval $<11$ hours $(8,27)$. Lastly, long weekly working hours was defined as working $>40$ hours and very long weekly working hours as working $>48$ hours per week.

\section{Statistical analysis}

A case-crossover design was used to compare the working hour characteristics of the four weeks preceding SA (exposure window) with those of the four weeks before the exposure window (control window). In case-crossover design, each participant serves as his or her own control. A conditional logistic regression model was used, and the odds ratios (OR) were controlled for the clustering effect of 338 retail stores, shift work, number of consecutive night shifts, weekly working hours $>40$ hours, the length of shifts, and percent of short shift intervals. We conducted stratified analyses to determine whether there were differences in the associations of working-hour characteristics with short SA between part- and full-time workers, men and women, and between younger and older workers. We used median to split age into two groups: (i) workers $<30$ years and (ii) workers aged $\geq 30$ years. Stata, version 15 (StataCorp LP, College Station, Texas) was used for the analyses.

\section{Results}

The study population worked at 338 retail stores of various sizes, including small grocery stores, supermarkets and hypermarkets. Of the participants, $77.2 \%$ were women, and $73.4 \%$ worked part-time and $26.6 \%$ fulltime according to employment contract (table 1). Participants were aged $15-74$ years. Nearly half were $<30$ years, and only $5 \%$ were $\geq 60$ years. The mean age of the participants was 34.6 [standard deviation (SD) 13.2] years, with men 32.2 (SD 11.5) years and women 35.4 (SD 13.5) years. A majority of the participants (64.4\%) worked in the capital area of Finland. On average, $48 \%$ of full-time employees and $14 \%$ of part-time employees worked $>40$ hours/week for $\geq 2$ weeks per month.
Table 1. The characteristics of the study population ( $\mathrm{N}=4046)$

\begin{tabular}{lrr}
\hline Characteristic & $\mathrm{N}$ & $\%$ \\
\hline Sex & & \\
Men & 911 & 22.5 \\
Women & 3083 & 76.2 \\
Missing & 52 & 1.3 \\
Age (years) & 187 & \\
15-19 & 1805 & 4.6 \\
$20-29$ & 772 & 44.6 \\
$30-39$ & 572 & 19.1 \\
$40-49$ & 509 & 14.1 \\
$50-59$ & 201 & 12.6 \\
$60-74$ & & 5.0 \\
Work schedule & 1078 & \\
Full-time & 2968 & 26.6 \\
Part-time & & 73.4 \\
Region & & \\
Capital area of Finland & 2607 & 64.4 \\
Middle-Finland & 707 & 17.5 \\
North-East Finland & 732 & 18.1 \\
\hline
\end{tabular}

\section{Work characteristics of short sickness absence}

All workers. Long weekly working hours, short shifts $(<4$ hours), percent and number of short shift intervals $(<11$ hours) during four weeks of the exposure window were associated with short SA, while types of shifts, number of consecutive night shifts, and long shifts ( $>9$ hours) were not associated with short SA (table 2). After adjustment for clustering effect and confounders, the risk of short SA was 1.52 times [95\% confidence interval (CI) $1.25-1.85$ ] higher among employees who worked $>40$ hours/week for $\geq 3$ weeks during four weeks of the exposure window. The risk of SA was 1.30 times $(95 \% \mathrm{CI}$ 1.09-1.56) higher among employees who worked $>48$ hours/week for $\geq 1$ week. Working night shift $\geq 1$ night in a month, and the percentage and number of weeks working night shifts in a month were not associated with short SA.

After adjustment for clustering effect and confounders, short SA was lower among workers who had short shifts [odds ratio (OR) $0.84,95 \%$ CI $0.70-0.99$ ]. The strongest associations were found between percent and number of short shift intervals ( $<11$ hours), and short SA. Compared with workers with no short shift intervals, the risk of SA was 1.47 times (95\% CI 1.29-1.68) higher among workers who had short shift intervals $\leq 10 \%$ of time during four weeks of the exposure window, 2.39 times (95\% CI 2.03-2.82) higher among workers who had short shift intervals $10-25 \%$ of time, and 4.03 times (95\% CI 2.34-6.93) higher among workers who had short shift intervals $>25 \%$ of time. The risk of short SA also increased with increasing in the number of short shift intervals. The risk was 1.57 times $(95 \%$ CI $1.40-1.76)$ higher among workers who had 2-4 short shift intervals in four weeks, 2.51 times (95\% CI 1.97-3.19) higher among those who had 5-11 short shift intervals, and 4.34 times (95\% CI 1.37-13.69) higher among those who had $\geq 12$ 
Table 2. Odds ratios (OR) for the associations between work characteristics and short sickness absence among all workers. Number of weeks working $>40$ hours per week and extended weekly working hours at least for a week were not included in the same model II. Percent and number of short shift intervals were not included in the same model II. [Cl=confidence interval.]

\begin{tabular}{|c|c|c|c|c|c|c|c|c|}
\hline \multirow[t]{2}{*}{ Characteristic } & \multicolumn{2}{|c|}{ Control window } & \multicolumn{2}{|c|}{ Exposure window } & \multicolumn{2}{|c|}{ Model I a } & \multicolumn{2}{|c|}{ Model II b } \\
\hline & $\mathrm{N}$ & $\%$ & $\mathrm{~N}$ & $\%$ & OR & $95 \% \mathrm{Cl}$ & OR & $95 \% \mathrm{Cl}$ \\
\hline \multicolumn{9}{|c|}{ Shift work ( $\geq 50 \%$ of 4 weeks) } \\
\hline Day & 126 & 3.1 & 113 & 2.8 & 0.87 & $0.60-1.26$ & 0.98 & $0.67-1.44$ \\
\hline Early morning & 966 & 23.9 & 939 & 23.2 & 0.68 & $0.48-0.97$ & 0.68 & $0.46-1.02$ \\
\hline Morning & 222 & 5.5 & 192 & 4.8 & 1 & & 1 & \\
\hline Evening & 1379 & 34.1 & 1316 & 32.5 & 0.95 & $0.78-1.17$ & 1.00 & $0.81-1.24$ \\
\hline Night & 180 & 4.4 & 187 & 4.6 & 1.26 & $0.81-1.96$ & 1.54 & $0.95-2.51$ \\
\hline Any shift (<50\%) & 1173 & 29.0 & 1299 & 32.1 & 1.19 & $0.99-1.43$ & 1.17 & $0.97-1.41$ \\
\hline \multicolumn{9}{|c|}{ Number of consecutive night shifts } \\
\hline 0 & 3273 & 80.9 & 3313 & 81.9 & 1 & & 1 & \\
\hline $1-2$ & 319 & 7.9 & 293 & 7.2 & 0.83 & $0.66-1.04$ & 0.80 & $0.63-1.02$ \\
\hline $3-4$ & 55 & 1.4 & 56 & 1.4 & 0.87 & $0.49-1.53$ & 0.81 & $0.48-1.40$ \\
\hline 5 & 134 & 3.3 & 133 & 3.3 & 0.83 & $0.59-1.17$ & 0.85 & $0.59-1.21$ \\
\hline$\geq 6$ & 265 & 6.5 & 251 & 6.2 & 0.71 & $0.47-1.07$ & 0.74 & $0.47-1.18$ \\
\hline \multicolumn{9}{|c|}{$\begin{array}{l}\text { Number of weeks working > } 40 \text { hour/week } \\
\text { for } 4 \text { weeks }\end{array}$} \\
\hline 0 & 1976 & 48.8 & 1916 & 47.4 & 1 & & & \\
\hline 1 & 1148 & 28.4 & 1188 & 29.3 & 1.10 & $0.98-1.22$ & 1.07 & $0.96-1.20$ \\
\hline 2 & 651 & 16.1 & 611 & 15.1 & 1.02 & $0.87-1.19$ & 1.00 & $0.85-1.18$ \\
\hline$\geq 3$ & 271 & 6.7 & 331 & 8.2 & 1.35 & $1.12-1.64$ & 1.52 & $1.25-1.85$ \\
\hline \multicolumn{9}{|c|}{$\begin{array}{l}\text { Extended weekly working hours at least for } \\
\text { a week / } 4 \text { weeks }\end{array}$} \\
\hline$<40$ & 1976 & 48.9 & 1916 & 47.4 & 1 & & 1 & \\
\hline $40-48$ & 1660 & 41.0 & 1664 & 41.1 & 1.07 & $0.96-1.19$ & 1.05 & 0.94-1.18 \\
\hline$>48$ & 410 & 10.1 & 466 & 10.5 & 1.25 & $1.04-1.50$ & 1.30 & $1.09-1.56$ \\
\hline \multicolumn{9}{|c|}{ Length of shifts (hours) } \\
\hline Medium (4-9) & 2251 & 55.6 & 2319 & 57.3 & 1 & & 1 & \\
\hline Short $(<4)$ & 564 & 13.9 & 521 & 12.9 & 0.83 & $0.70-0.98$ & 0.84 & $0.70-0.99$ \\
\hline Long $(>9)$ & 1027 & 25.4 & 1019 & 25.2 & 0.94 & $0.83-1.07$ & 0.91 & 0.79-1.05 \\
\hline Short and long & 204 & 5.1 & 187 & 4.6 & 0.83 & $0.65-1.07$ & 0.79 & $0.61-1.01$ \\
\hline \multicolumn{9}{|c|}{ Percent of short ( $<11$ hours) shift intervals } \\
\hline 0 & 1134 & 28.0 & 823 & 20.3 & 1 & & 1 & \\
\hline$\leq 10$ & 1841 & 45.5 & 1774 & 43.8 & 1.45 & $1.28-1.65$ & 1.47 & $1.29-1.68$ \\
\hline $10.1-25$ & 1025 & 25.3 & 1382 & 34.2 & 2.33 & $1.98-2.74$ & 2.39 & $2.03-2.82$ \\
\hline$>25$ & 46 & 1.2 & 67 & 1.7 & 3.97 & $2.31-6.81$ & 4.03 & $2.34-6.93$ \\
\hline \multirow{2}{*}{\multicolumn{9}{|c|}{$\begin{array}{l}\text { Number of short ( }<11 \text { hours) shift intervals } \\
\text { / } 4 \text { weeks }\end{array}$}} \\
\hline & & & & & & & & \\
\hline $0-1$ & 2178 & 53.8 & 1799 & 44.5 & 1 & & 1 & \\
\hline $2-4$ & 1597 & 39.5 & 1838 & 45.4 & 1.55 & $1.39-1.74$ & 1.57 & $1.40-1.76$ \\
\hline $5-11$ & 262 & 6.5 & 398 & 9.8 & 2.49 & $1.96-3.16$ & 2.51 & $1.97-3.19$ \\
\hline$\geq 12$ & 9 & 0.2 & 11 & 0.3 & 3.71 & $1.36-10.14$ & 4.34 & $1.37-13.69$ \\
\hline
\end{tabular}

a Model I: Adjusted for clustering effect.

${ }^{b}$ Model II: Adjusted for clustering effect, shift work, number of consecutive night shifts, number of weeks working longer than 40 hours per week, length of shifts, and percent of short shift intervals.

short shift intervals compared with workers who had 0 or 1 short shift interval in four weeks.

Full-time versus part-time workers. The risk of SA strongly increased with increasing in percent of short shift intervals during four weeks of the exposure window among both full- and part-time workers (table 3). Among fulltime workers, the risk of short SA was 2.41 times (95\% CI 0.99-5.86) higher when working mainly night shifts and 1.38 times $(95 \%$ CI $1.00-1.91)$ higher when working any shift for $<50 \%$ compared with morning shifts. The risk of SA was lower among full-time employees who worked either short shifts (OR $0.65,95 \%$ CI 0.42 0.98 ) or a combination of short and long shifts (OR 0.61, 95\% CI 0.37-0.99) than those who worked 4-9 hours shifts. Among part-time workers, the risk of SA was 2.22 times (95\% CI 1.65-2.98) higher among employees who worked $>40$ hours/week for 3 or 4 weeks and 1.51 times (95\% CI 1.19-1.92) higher among employees who worked $>48$ hours/week for at least one week during four weeks of the exposure window. The number of consecutive night shifts, working night shift at least once a month, and the percentage and number of weeks working night shifts in a month were not associated with short SA among both full-time and part-time workers.

Men versus women. Among both men and women, the risk of short SA strongly increased with increasing in percent of short shift intervals (table 4). Among women, the risk of short SA was 1.72 times (95\% CI 1.02-2.89) higher when working mainly night compared with morning shifts. The risk of SA was 1.62 times (95\% CI 1.27-2.07) higher among women who worked $>40$ hours/week for 3 or 4 weeks and 1.25 times ( $95 \%$ CI $1.00-1.56)$ higher 
Table 3. Odds ratios (OR) for the associations between work characteristics and short sickness absence among part-time and full-time workers. Number of weeks working $>40$ hours per week and extended weekly working hours at least for a week were not included in the same model. $[\mathrm{Cl}=$ confidence interval.]

\begin{tabular}{|c|c|c|c|c|c|c|c|c|c|c|c|c|}
\hline \multirow[t]{3}{*}{ Characteristic } & \multicolumn{6}{|c|}{ Full-time (N=1078) } & \multicolumn{6}{|c|}{ Part-time (N=2968) } \\
\hline & \multicolumn{2}{|c|}{ Control window } & \multicolumn{2}{|c|}{ Exposure window } & \multirow[t]{2}{*}{$\mathrm{OR}^{\mathrm{a}}$} & \multirow[t]{2}{*}{$95 \% \mathrm{Cl}$} & \multicolumn{2}{|c|}{ Control window } & \multicolumn{2}{|c|}{ Exposure window } & \multirow[t]{2}{*}{$\mathrm{OR}^{\mathrm{a}}$} & \multirow[t]{2}{*}{$95 \% \mathrm{Cl}$} \\
\hline & $\mathrm{N}$ & $\%$ & $\mathrm{~N}$ & $\%$ & & & $\mathrm{~N}$ & $\%$ & $\mathrm{~N}$ & $\%$ & & \\
\hline \multicolumn{13}{|l|}{$\begin{array}{l}\text { Shift work (>50\% } \\
\text { of } 4 \text { weeks) }\end{array}$} \\
\hline Day & 19 & 1.8 & 11 & 1.0 & 0.58 & $0.18-1.88$ & 107 & 3.6 & 102 & 3.5 & 1.01 & $0.66-1.55$ \\
\hline Early morning & 90 & 8.3 & 76 & 44.6 & 0.52 & $0.23-1.13$ & 132 & 4.5 & 116 & 3.9 & 0.74 & $0.44-1.26$ \\
\hline Morning & 495 & 45.9 & 481 & 7.1 & 1 & & 471 & 15.9 & 458 & 15.4 & 1 & \\
\hline Evening & 162 & 15.0 & 147 & 13.7 & 0.99 & $0.65-1.51$ & 1217 & 41.0 & 1169 & 39.4 & 0.98 & $0.77-1.25$ \\
\hline Night & 45 & 4.2 & 50 & 4.6 & 2.41 & $0.99-5.86$ & 135 & 4.6 & 137 & 4.6 & 1.35 & $0.82-2.25$ \\
\hline Any shift (<50\%) & 267 & 24.8 & 313 & 29.0 & 1.38 & $1.00-1.91$ & 906 & 30.5 & 986 & 33.2 & 1.11 & $0.88-1.40$ \\
\hline \multicolumn{13}{|l|}{$\begin{array}{l}\text { Number of } \\
\text { consecutive night } \\
\text { shifts }\end{array}$} \\
\hline 0 & 852 & 79.1 & 864 & 80.1 & 1 & & 2421 & 81.6 & 2449 & 82.5 & 1 & \\
\hline $1-2$ & 91 & 8.4 & 88 & 8.2 & 0.78 & $0.49-1.23$ & 228 & 7.7 & 205 & 6.9 & 0.79 & $0.62-1.01$ \\
\hline $3-4$ & 13 & 1.2 & 9 & 0.8 & 0.48 & $0.13-1.71$ & 42 & 1.4 & 47 & 1.6 & 0.96 & $0.53-1.72$ \\
\hline 5 & 38 & 3.5 & 34 & 3.2 & 0.79 & $0.31-2.08$ & 96 & 3.2 & 99 & 3.3 & 0.88 & $0.57-1.34$ \\
\hline$\geq 6$ & 84 & 7.8 & 83 & 7.7 & 0.99 & $0.40-2.42$ & 181 & 6.1 & 168 & 5.7 & 0.69 & $0.41-1.16$ \\
\hline \multicolumn{13}{|l|}{$\begin{array}{l}\text { Number of weeks } \\
\text { working }>40 \text { hour/ } \\
\text { week in } 4 \text { weeks }\end{array}$} \\
\hline 0 & 210 & 19.5 & 225 & 20.9 & 1 & & 1766 & 59.5 & 1691 & 57.0 & 1 & \\
\hline 1 & 339 & 31.5 & 347 & 32.2 & 1.00 & $0.78-1.28$ & 809 & 27.2 & 841 & 28.3 & 1.09 & $0.96-1.25$ \\
\hline 2 & 340 & 31.5 & 317 & 29.4 & 0.90 & $0.69-1.19$ & 311 & 10.5 & 294 & 9.9 & 1.02 & $0.84-1.25$ \\
\hline$>3$ & 189 & 17.5 & 189 & 17.5 & 1.17 & $0.83-1.65$ & 82 & 2.8 & 142 & 4.8 & 2.22 & $1.65-2.98$ \\
\hline \multicolumn{13}{|l|}{$\begin{array}{l}\text { Extended weekly } \\
\text { working hours at } \\
\text { least for a week / } 4 \\
\text { weeks }\end{array}$} \\
\hline$<40$ & 210 & 19.5 & 225 & 20.9 & 1 & & 1766 & 59.5 & 1691 & 57.0 & 1 & \\
\hline $40-48$ & 630 & 58.4 & 613 & 56.9 & 0.95 & $0.75-1.21$ & 1030 & 34.7 & 1051 & 35.4 & 1.08 & $0.95-1.23$ \\
\hline$>48$ & 238 & 22.1 & 240 & 22.2 & 1.09 & $0.81-1.46$ & 172 & 5.8 & 226 & 7.6 & 1.51 & $1.19-1.92$ \\
\hline \multicolumn{13}{|l|}{$\begin{array}{l}\text { Length of shifts } \\
\text { (hours) }\end{array}$} \\
\hline Medium (4-9) & 505 & 46.8 & 540 & 50.1 & 1 & & 1746 & 58.9 & 1779 & 59.9 & 1 & \\
\hline Short $(<4)$ & 130 & 12.1 & 116 & 10.7 & 0.65 & $0.42-0.98$ & 434 & 14.6 & 405 & 13.7 & 0.88 & $0.72-1.07$ \\
\hline Long (>9) & 376 & 34.9 & 363 & 33.7 & 0.86 & $0.65-1.15$ & 651 & 21.9 & 656 & 22.1 & 0.93 & $0.80-1.09$ \\
\hline Short and long & 67 & 6.2 & 59 & 5.5 & 0.61 & $0.37-0.99$ & 137 & 4.6 & 128 & 4.3 & 0.87 & $0.64-1.16$ \\
\hline \multicolumn{13}{|l|}{$\begin{array}{l}\% \text { of short }(<11 \\
\text { hours) shift } \\
\text { intervals }\end{array}$} \\
\hline 0 & 255 & 23.6 & 145 & 13.5 & 1 & & 879 & 29.6 & 678 & 22.8 & 1 & \\
\hline$<10$ & 487 & 45.2 & 438 & 40.6 & 1.83 & $1.38-2.41$ & 1354 & 45.6 & 1336 & 45.0 & 1.40 & $1.21-1.62$ \\
\hline $10.1-25$ & 316 & 29.3 & 465 & 43.1 & 3.73 & $2.70-5.15$ & 709 & 23.9 & 917 & 30.9 & 2.06 & $1.74-2.44$ \\
\hline$>25$ & 20 & 1.9 & 30 & 2.8 & 6.81 & $2.47-18.75$ & 26 & 0.9 & 37 & 1.3 & 3.12 & $1.62-6.01$ \\
\hline
\end{tabular}

${ }^{a}$ Adjusted for clustering effect, shift work, number of consecutive night shifts, number of weeks working longer than 40 hours per week, length of shifts, and percent of short shift intervals.

among women who worked $>48$ hours/week for at least a week during four weeks of the exposure window compared with women who did not work $>40$ hours/week at any time during the four weeks. Moreover, women who worked only short shifts had lower SA (OR 0.79, 95\% CI 0.65-0.97) than women who worked medium length shifts (4-9 hours). Among men, those who worked $>48$ hours/week for at least a week during four weeks of the exposure window had 1.45 times (95\% CI 1.03-2.05) higher risk of short SA than men who did not work $>40$ hours/week at any time during the four weeks. The types of shift work, and length of work shift were not associated with short SA among men (table 4). The number of consecutive night shifts, working night shift for at least once a month, and the percentage and number of weeks working night shifts in a month were not associated with short SA among both men and women.

Younger ( $<30$ years) versus older workers ( $\geq 30$ years). Among both younger and older workers, the risk of short SA strongly increased with increasing percent of short shift intervals (table 5). In workers $<30$ years, the risk of SA was 1.68 times (95\% CI 1.20-2.35) higher among those who worked $>40$ hours/week for 3-4 weeks and 1.35 times (95\% CI 1.03-1.77) higher among employees who worked $>48$ hours/week for at least a week during four weeks of the exposure window. In workers aged $\geq 30$ years, the risk of SA were 1.43 times (95\% CI 1.07-1.92) higher among those who worked $>40$ hours/week for 3-4 weeks, and 1.39 times (95\% CI 1.11-1.75) higher when 
Table 4. Odds ratios (OR) for the associations between work characteristics and short sickness absence among men and women. Number of weeks working $>40$ hours per week and extended weekly working hours at least for a week were not included in the same model. [Cl=confidence interval.]

\begin{tabular}{|c|c|c|c|c|c|c|c|c|c|c|c|c|}
\hline \multirow[t]{3}{*}{ Characteristic } & \multicolumn{6}{|c|}{ Men $(\mathrm{N}=911)$} & \multicolumn{6}{|c|}{ Women $(\mathrm{N}=3083)$} \\
\hline & \multicolumn{2}{|c|}{ Control window } & \multicolumn{2}{|c|}{ Exposure window } & \multirow[t]{2}{*}{$\mathrm{OR}^{\mathrm{a}}$} & \multirow[t]{2}{*}{$95 \% \mathrm{Cl}$} & \multicolumn{2}{|c|}{ Control window } & \multicolumn{2}{|c|}{ Exposure window } & \multirow[t]{2}{*}{$\mathrm{OR}^{\mathrm{a}}$} & \multirow[t]{2}{*}{$95 \% \mathrm{Cl}$} \\
\hline & $\mathrm{N}$ & $\%$ & $\mathrm{~N}$ & $\%$ & & & $\mathrm{~N}$ & $\%$ & $\mathrm{~N}$ & $\%$ & & \\
\hline \multicolumn{13}{|l|}{$\begin{array}{l}\text { Shift work (>50\% } \\
\text { of } 4 \text { weeks) }\end{array}$} \\
\hline Day & 24 & 2.6 & 21 & 2.3 & 1.23 & $0.51-2.95$ & 99 & 3.2 & 87 & 2.8 & 0.86 & $0.58-1.29$ \\
\hline Early morning & 56 & 6.2 & 50 & 5.5 & 0.75 & $0.31-1.84$ & 166 & 5.4 & 141 & 4.6 & 0.64 & $0.37-1.10$ \\
\hline Morning & 224 & 24.6 & 214 & 23.5 & 1 & & 730 & 23.7 & 717 & 23.2 & 1 & \\
\hline Evening & 301 & 33.0 & 303 & 33.3 & 1.28 & $0.78-2.10$ & 1052 & 34.1 & 986 & 32.0 & 0.91 & $0.72-1.15$ \\
\hline Night & 67 & 7.4 & 64 & 7.0 & 1.27 & $0.58-2.78$ & 111 & 3.6 & 122 & 4.0 & 1.72 & $1.02-2.89$ \\
\hline Any shift (<50\%) & 239 & 26.2 & 259 & 28.4 & 1.30 & $0.87-1.94$ & 925 & 30.0 & 1030 & 33.4 & 1.10 & $0.89-1.35$ \\
\hline \multicolumn{13}{|c|}{$\begin{array}{l}\text { Number of consecutive } \\
\text { night shifts }\end{array}$} \\
\hline 0 & 665 & 73.0 & 684 & 75.1 & 1 & & 2561 & 83.0 & 2579 & 83.7 & 1 & \\
\hline $1-2$ & 94 & 10.3 & 81 & 8.9 & 0.71 & $0.46-1.10$ & 224 & 7.3 & 210 & 6.8 & 0.86 & $0.65-1.12$ \\
\hline $3-4$ & 20 & 2.2 & 25 & 2.7 & 0.91 & $0.45-1.82$ & 34 & 1.1 & 31 & 1.0 & 0.80 & $0.37-1.70$ \\
\hline 5 & 42 & 4.6 & 37 & 4.1 & 0.58 & $0.30-1.14$ & 92 & 3.0 & 96 & 3.1 & 1.06 & $0.69-1.64$ \\
\hline$\geq 6$ & 90 & 9.9 & 84 & 9.2 & 0.56 & $0.27-1.15$ & 172 & 5.6 & 167 & 5.4 & 0.88 & $0.49-1.58$ \\
\hline \multicolumn{13}{|c|}{$\begin{array}{l}\text { Number of weeks work- } \\
\text { ing }>40 \text { hours/week in } \\
4 \text { weeks }\end{array}$} \\
\hline 0 & 439 & 48.2 & 432 & 47.4 & 1 & & 1503 & 48.8 & 1443 & 46.8 & 1 & \\
\hline 1 & 256 & 28.1 & 264 & 29.0 & 1.08 & $0.86-1.34$ & 880 & 28.5 & 917 & 29.7 & 1.10 & $0.96-1.25$ \\
\hline 2 & 150 & 16.5 & 147 & 16.1 & 1.08 & $0.79-1.48$ & 495 & 16.1 & 464 & 15.1 & 1.01 & $0.83-1.22$ \\
\hline$>3$ & 66 & 7.2 & 68 & 7.5 & 1.24 & $0.81-1.88$ & 205 & 6.6 & 259 & 8.4 & 1.62 & $1.27-2.07$ \\
\hline \multicolumn{13}{|c|}{$\begin{array}{l}\text { Extended weekly working } \\
\text { hours at least for a week } \\
\text { / } 4 \text { weeks }\end{array}$} \\
\hline$<40$ & 439 & 48.2 & 432 & 47.4 & 1 & & 1503 & 48.7 & 1443 & 46.8 & 1 & \\
\hline $40-48$ & 373 & 40.9 & 361 & 39.6 & 1.04 & $0.84-1.30$ & 1270 & 41.2 & 1300 & 42.2 & 1.08 & $0.95-1.24$ \\
\hline$>48$ & 99 & 10.9 & 118 & 13.0 & 1.45 & $1.03-2.05$ & 310 & 10.1 & 340 & 11.0 & 1.25 & $1.00-1.56$ \\
\hline \multicolumn{13}{|c|}{ Length of shifts (hours) } \\
\hline Medium (4-9) & 1734 & 56.2 & 1774 & 57.6 & 1 & & 480 & 52.7 & 498 & 54.7 & 1 & \\
\hline Short (<4) & 408 & 13.2 & 365 & 11.8 & 1.00 & $0.71-1.42$ & 152 & 16.7 & 156 & 17.1 & 0.79 & $0.65-0.97$ \\
\hline Long $(>9)$ & 786 & 25.5 & 796 & 25.8 & 0.84 & $0.64-1.10$ & 232 & 25.5 & 218 & 23.9 & 0.95 & $0.81-1.11$ \\
\hline Short and long & 155 & 5.0 & 148 & 4.8 & 0.80 & $0.47-1.37$ & 47 & 5.1 & 39 & 4.3 & 0.80 & $0.61-1.05$ \\
\hline \multicolumn{13}{|c|}{$\begin{array}{l}\% \text { of short }(<11 \text { hours) } \\
\text { shift intervals }\end{array}$} \\
\hline 0 & 276 & 30.3 & 215 & 23.6 & 1 & & 843 & 27.3 & 573 & 18.6 & 1 & \\
\hline$<10$ & 400 & 43.9 & 406 & 44.5 & 1.44 & $1.10-1.87$ & 1417 & 46.0 & 1356 & 44.0 & 1.58 & $1.36-1.83$ \\
\hline $10.1-25$ & 222 & 24.4 & 273 & 30.0 & 1.90 & $1.43-2.53$ & 791 & 25.7 & 1104 & 35.8 & 2.74 & $2.27-3.30$ \\
\hline$>25$ & 13 & 1.4 & 17 & 1.9 & 3.38 & $1.15-9.93$ & 32 & 1.0 & 50 & 1.6 & 4.74 & $2.72-8.28$ \\
\hline
\end{tabular}

a Adjusted for clustering effect, shift work, number of consecutive night shifts, number of weeks working $>40$ hours per week, length of shifts, and percent of short shift intervals.

they worked any shift for $<50 \%$ compared with morning workers. The risk of SA was lower among employees who worked either short shifts (OR 0.75, 95\% CI 0.57-0.98) or a combination of short and long shifts (OR $0.60,95 \%$ CI $0.42-0.86$ ). The number of consecutive night shifts, working night shift for at least once a month, and the percentage and number of weeks working night shifts in a month were not associated with short SA among both younger and older workers.

\section{Discussion}

The present study showed that among factors related to shift work in the retail sector, a short shift interval is the stronger risk factor for short SA. Moreover, long weekly working hours increased the risk of short SA among part-time workers and working mainly night shifts increased the risk among full-time workers.

We found a strong dose-response relationship between a short interval between shifts (quick return) and short SA. A dose-response relationship was found among both part- and full-time workers, both men and women, and among both younger and older workers. In line with the current study, an earlier study utilizing objectively measured working hour characteristics among Norwegian nurses found a dose-response relationship between quick returns $(<11$ hours of rest between shifts) and SA (8). Furthermore, another study (5) also utilizing register-based data on working-hour characteristics found a short interval between work shifts increases the risk of short SA among Finnish hospital workers. However, an intervention aiming to increase interval between shifts improved sleep duration, alertness and well-being at work, but had no benefi- 
Table 5. Odds ratios (OR) for associations between work characteristics and short sickness absence among younger (<30 years) and older (>30 years) workers. Number of weeks working $>40$ per week and extended weekly working hours at least for a week were not included in the same model. [Cl=confidence interval.]

\begin{tabular}{|c|c|c|c|c|c|c|c|c|c|c|c|c|}
\hline \multirow[t]{3}{*}{ Characteristic } & \multicolumn{6}{|c|}{$<30$ years $(\mathrm{N}=1992)$} & \multicolumn{6}{|c|}{$>30$ years $(2054)$} \\
\hline & \multicolumn{2}{|c|}{ Control window } & \multicolumn{2}{|c|}{ Exposure window } & \multirow[t]{2}{*}{$\mathrm{OR}^{\mathrm{a}}$} & \multirow[t]{2}{*}{$95 \% \mathrm{Cl}$} & \multicolumn{2}{|c|}{ Control window } & \multicolumn{2}{|c|}{ Exposure window } & \multirow[t]{2}{*}{$\mathrm{OR}^{\mathrm{a}}$} & \multirow[t]{2}{*}{$95 \% \mathrm{Cl}$} \\
\hline & $\mathrm{N}$ & $\%$ & $\mathrm{~N}$ & $\%$ & & & $\mathrm{~N}$ & $\%$ & $\mathrm{~N}$ & $\%$ & & \\
\hline \multicolumn{13}{|c|}{$\begin{array}{l}\text { Shift work (>50\% of } \\
4 \text { weeks) }\end{array}$} \\
\hline Day & 54 & 2.7 & 53 & 2.7 & 0.91 & $0.52-1.61$ & 72 & 3.5 & 60 & 2.9 & 1.02 & $0.58-1.79$ \\
\hline Early morning & 92 & 4.6 & 81 & 4.1 & 0.63 & $0.38-1.03$ & 130 & 6.3 & 111 & 5.4 & 0.72 & $0.39-1.34$ \\
\hline Morning & 311 & 15.6 & 316 & 15.8 & 1 & & 655 & 31.9 & 623 & 30.3 & 1 & \\
\hline Evening & 849 & 42.7 & 819 & 41.1 & 0.87 & $0.65-1.17$ & 530 & 25.8 & 497 & 24.2 & 1.12 & $0.84-1.48$ \\
\hline Night & 108 & 5.4 & 113 & 5.7 & 1.31 & $0.78-2.18$ & 72 & 3.5 & 74 & 3.6 & 1.73 & $0.79-3.78$ \\
\hline Any shift $(<50 \%)$ & 578 & 29.0 & 610 & 30.6 & 0.96 & $0.73-1.25$ & 595 & 29.0 & 689 & 33.6 & 1.39 & $1.11-1.75$ \\
\hline \multicolumn{13}{|c|}{$\begin{array}{l}\text { Number of consecu- } \\
\text { tive night shifts }\end{array}$} \\
\hline 0 & 1539 & 77.2 & 1555 & 78.1 & 1 & & 1734 & 84.4 & 1758 & 85.6 & 1 & \\
\hline $1-2$ & 177 & 8.9 & 170 & 8.5 & 0.85 & $0.62-1.17$ & 142 & 6.9 & 123 & 6.0 & 0.75 & $0.56-1.01$ \\
\hline $3-4$ & 39 & 2.0 & 40 & 2.0 & 0.86 & $0.46-1.61$ & 16 & 0.8 & 16 & 0.8 & 0.82 & $0.32-2.07$ \\
\hline 5 & 83 & 4.2 & 81 & 4.1 & 0.80 & $0.51-1.28$ & 51 & 2.5 & 52 & 2.5 & 0.91 & $0.47-1.76$ \\
\hline$\geq 6$ & 154 & 7.7 & 146 & 7.3 & 0.77 & $0.40-1.48$ & 111 & 5.4 & 105 & 5.1 & 0.71 & $0.38-1.35$ \\
\hline \multicolumn{13}{|c|}{$\begin{array}{l}\text { Number of weeks } \\
\text { working }>40 \text { hours/ } \\
\text { week in } 4 \text { weeks }\end{array}$} \\
\hline 0 & 1138 & 57.1 & 1093 & 54.9 & 1 & & 838 & 40.8 & 823 & 40.1 & 1 & \\
\hline 1 & 534 & 26.8 & 547 & 27.4 & 1.06 & $0.91-1.24$ & 614 & 29.9 & 641 & 31.2 & 1.08 & $0.90-1.28$ \\
\hline 2 & 226 & 11.4 & 233 & 11.7 & 1.12 & $0.90-1.40$ & 425 & 20.7 & 378 & 18.4 & 0.92 & $0.73-1.14$ \\
\hline$>3$ & 94 & 4.7 & 119 & 6.0 & 1.68 & $1.20-2.35$ & 177 & 8.6 & 212 & 10.3 & 1.43 & $1.07-1.92$ \\
\hline \multicolumn{13}{|l|}{$\begin{array}{l}\text { Extended weekly } \\
\text { working hours at } \\
\text { least for a week / } 4 \\
\text { weeks }\end{array}$} \\
\hline$<40$ & 1138 & 57.1 & 1093 & 54.9 & 1 & & 838 & 40.8 & 823 & 40.1 & 1 & \\
\hline $40-48$ & 701 & 35.2 & 717 & 36.0 & 1.07 & $0.93-1.24$ & 959 & 46.7 & 947 & 46.1 & 1.03 & $0.87-1.22$ \\
\hline$>48$ & 153 & 7.7 & 182 & 9.1 & 1.35 & $1.03-1.77$ & 257 & 12.5 & 284 & 13.8 & 1.27 & 0.98-1.65 \\
\hline \multicolumn{13}{|l|}{$\begin{array}{l}\text { Length of shifts } \\
\text { (hours) }\end{array}$} \\
\hline Medium (4-9) & 1113 & 55.9 & 1123 & 56.4 & 1 & & 1138 & 55.4 & 1196 & 58.2 & 1 & \\
\hline Short $(<4)$ & 316 & 15.9 & 298 & 14.9 & 0.92 & $0.73-1.16$ & 248 & 12.1 & 223 & 10.9 & 0.75 & $0.57-0.98$ \\
\hline Long $(>9)$ & 461 & 23.1 & 468 & 23.5 & 0.97 & $0.79-1.19$ & 566 & 27.5 & 551 & 26.8 & 0.88 & $0.74-1.04$ \\
\hline Short and long & 102 & 5.1 & 103 & 5.2 & 0.97 & $0.69-1.36$ & 102 & 5.0 & 84 & 4.1 & 0.60 & $0.42-0.86$ \\
\hline \multicolumn{13}{|c|}{$\begin{array}{l}\% \text { of short (<11 } \\
\text { hours) shift intervals }\end{array}$} \\
\hline 0 & 616 & 30.9 & 469 & 23.5 & 1 & & 518 & 25.2 & 354 & 17.2 & 1 & \\
\hline$<10$ & 885 & 44.4 & 876 & 44.0 & 1.44 & $1.22-1.70$ & 956 & 46.5 & 898 & 43.7 & 1.51 & $1.25-1.83$ \\
\hline $10.1-25$ & 471 & 23.7 & 625 & 31.4 & 2.22 & $1.77-2.79$ & 554 & 27.0 & 757 & 36.9 & 2.60 & $2.07-3.26$ \\
\hline$>25$ & 20 & 1.0 & 22 & 1.1 & 2.19 & $1.01-4.76$ & 26 & 1.3 & 45 & 2.2 & 6.15 & $2.89-13.08$ \\
\hline
\end{tabular}

${ }^{a}$ Adjusted for clustering effect, shift work, number of consecutive night shifts, number of weeks working longer than 40 hours per week, length of shifts, and percent of short shift intervals.

cial effect on the number of SA days (28). However, that study (28) recruited only 75 nurses, and the study had low statistical power to determine the effect of increasing interval between evening and morning shifts on the occurrence of SA. Quick return has adverse effects on sleep duration and causes sleepiness and fatigue (29) and can lead to absence from work.

To date, the association between shift work and SA is still uncertain. Some previous studies found that night shifts increase the risk of SA $(2,3,5,10,11)$, while other studies found that evening shifts $(4,10)$ or rotating 2- or 3-shift $(3,12,30)$ increase the risk of SA. Moreover, a study found no association between night shifts and long-term SA (12). Fixed night shifts (3), shift work including nightwork (night shift, 3-shift work, or rostered work including nights) (2) and working over $75 \%$ of time as night shifts (11) were associated with
SA. Earlier studies reported inconsistent results on the association between consecutive night shifts and SA (5, $10)$. Working consecutive night shifts was associated with SA among Danish (10) but not Finnish $(10,23)$ healthcare workers. In the current study, we also found no association between consecutive night shifts and SA. The association between working $\geq 50 \%$ of time as night shifts and SA was found only among full-time workers and women. Night shift work can reduce sleep duration and sleep quality (31) and can cause mild depressive symptoms (2), which lead to a higher rate of SA. However, further large prospective studies are needed to confirm a positive link between night shift and SA.

Earlier studies showed that the rate of short SA is more common among hospital workers with extended weekly working hours $(5,23)$. In line with an earlier study among healthcare workers (23), we found that 
weekly working hours $>40$ hours increase the risk of short SA among both younger and older workers. The current study adds to our knowledge that working $>40$ hours per week increases the risk of short SA among women and part-time workers, whereas working $>48$ hours per week increases the risk among men. A study among healthcare workers (7) found an increase in the risk of short SA by $0.7-1.0 \%$ per week after introduction of the policy of extending shift length from 8 to 12 hours. Reduced sleep duration in employees who work long weekly hours (32) or long shift may play a role in their increased risk of short SA. Extended weekly working hours may also cause more fatigue among part- compared to full-time workers.

The study had some strengths and limitations. The study recruited a relatively large and representative sample of retail workers. Registry-based data on working hour characteristics in the shift work and SA were utilized. Furthermore, a case-crossover design was used, and each participant served as his or her control, which controlled the observed risk differences for the confounding effects of individual factors. However, the participants might have changed their level of exposure to physical and psychosocial factors during the exposure window. As a limitation of the current study, no information on exposure to workload and psychosocial factors was collected. However, the lag was limited to a maximum of four weeks. A 4-week lag between control and exposure windows is more optimal than a shorter or longer lag. A 4-week lag is needed to observe changes to shift patterns and working hour characteristics, while it is a short period to observe any meaningful changes in exposure to physical workload factors among workers with the same tasks. An earlier case-crossover study among healthcare workers (5) found that a 1-week and a 3-month lags between control and exposure windows produce the results similar to a 4-week lag. Lastly, some differences in working hour characteristics between exposure and control windows might have happened because of seasonal variation.

\section{Concluding remarks}

The findings of the current study suggest that of working hour characteristics, a short shift interval is the most important risk factor for short SA among retail workers and avoiding it could reduce the risk of short SA. Moreover, shortening long weekly working hours, particularly among women, part-time workers and those $<30$ years could reduce the risk of short SA.

\section{Funding source}

The Finnish Work Environment Fund (Grant \# 190124) supported this study.

\section{Conflict of interest}

The authors declare no conflicts of interest.

\section{References}

1. Kreis J, Bödeker W. Indicators forwork-related health monitoring in Europe. Essen, Germany: Federal Association of Company Health Insurance Funds, Health Department; 2004. Report No.: 33

2. Tucker P, Peristera P, Leineweber C, Kecklund G. Can psychosocial working conditions help to explain the impact of shiftwork on health in male- and female-dominated occupations? A prospective cohort study. Chronobiol Int 2020 Sep;1-9. https://doi.org/10.1080/07420528.2020.180 5458 .

3. Bernstrøm VH, Houkes I. Shift work and sickness absence at a Norwegian hospital: a longitudinal multilevel study. Occup Environ Med 2020 Aug;77(8):555-63. https://doi. org/10.1136/oemed-2019-106240.

4. Merkus SL, van Drongelen A, Holte KA, Labriola M, Lund $\mathrm{T}$, van Mechelen $\mathrm{W}$ et al. The association between shift work and sick leave: a systematic review. Occup Environ Med 2012 Oct;69(10):701-12. https://doi.org/10.1136/ oemed-2011-100488.

5. Ropponen A, Koskinen A, Puttonen S, Härmä M. Exposure to working-hour characteristics and short sickness absence in hospital workers: A case-crossover study using objective data. Int J Nurs Stud 2019 Mar;91:14-21. https://doi. org/10.1016/j.ijnurstu.2018.11.002.

6. Dall'Ora C, Ball J, Redfern O, Recio-Saucedo A, Maruotti A, Meredith $\mathrm{P}$ et al. Are long nursing shifts on hospital wards associated with sickness absence? A longitudinal retrospective observational study. J Nurs Manag 2019 Jan;27(1):19-26. https://doi.org/10.1111/jonm.12643.

7. Rodriguez Santana I, Anaya Montes M, Chalkley M, Jacobs R, Kowalski T, Suter J. The impact of extending nurse working hours on staff sickness absence: evidence from a large mental health hospital in England. Int J Nurs Stud 2020 Dec;112:103611. https://doi.org/10.1016/j. ijnurstu.2020.103611.

8. Vedaa $\varnothing$, Pallesen S, Waage S, Bjorvatn B, Sivertsen B, Erevik E et al. Short rest between shift intervals increases the risk of sick leave: a prospective registry study. Occup Environ Med 2017 Jul;74(7):496-501. https://doi. org/10.1136/oemed-2016-103920.

9. Sandmark H. Work and family: associations with long-term sick-listing in Swedish women - a case-control study. BMC Public Health 2007 Oct; 7:287. https://doi.org/10.1186/14712458-7-287.

10. Larsen AD, Ropponen A, Hansen J, Hansen AM, Kolstad HA, Koskinen A et al. Working time characteristics and longterm sickness absence among Danish and Finnish nurses: A 
register-based study. Int J Nurs Stud 2020 Dec;112:103639. https://doi.org/10.1016/j.ijnurstu.2020.103639.

11. Dall'Ora C, Ball J, Redfern OC, Griffiths P. Night work for hospital nurses and sickness absence: a retrospective study using electronic rostering systems. Chronobiol Int 2020 Aug; $1-8$.

12. van Drongelen A, Boot CR, Hlobil H, van der Beek AJ, Smid T. Cumulative exposure to shift work and sickness absence: associations in a five-year historic cohort. BMC Public Health 2017 Jan;17(1):67. https://doi.org/10.1186/ s12889-016-3906-z.

13. Occupational Safety and Health Administration. Ergonomics for the prevention of musculoskeletal disorders: Guidelines for retail grocery stores. U.S. Department of Labor; 2004.

14. Niedhammer I, Landre MF, LeClerc A, Bourgeois F, Franchi P, Chastang JF et al. Shoulder disorders related to work organization and other occupational factors among supermarket cashiers. Int J Occup Environ Health 1998 JulSep;4(3):168-78. https://doi.org/10.1179/oeh.1998.4.3.168.

15. Bonfiglioli R, Mattioli S, Fiorentini C, Graziosi F, Curti $\mathrm{S}$, Violante FS. Relationship between repetitive work and the prevalence of carpal tunnel syndrome in part-time and full-time female supermarket cashiers: a quasi-experimental study. Int Arch Occup Environ Health 2007 Jan;80(3):248 53. https://doi.org/10.1007/s00420-006-0129-0.

16. Osorio AM, Ames RG, Jones J, Castorina J, Rempel D, Estrin W et al. Carpal tunnel syndrome among grocery store workers. Am J Ind Med 1994 Feb;25(2):229-45. https://doi. org/10.1002/ajim.4700250209

17. Balogh I, Ohlsson K, Nordander C, Bjork J, Hansson GA. The importance of work organization on workload and musculoskeletal health--Grocery store work as a model. Appl Ergon 2016;53 Pt A:143-51.

18. Graziosi F, Bonfiglioli R, Violante FS. [Occupational risks in grocery stores]. Ital Med Lav Ergon 2014;36(4):219-25.

19. Pekkala J, Rahkonen O, Pietiläinen O, Lahelma E, Blomgren J. Sickness absence due to different musculoskeletal diagnoses by occupational class: a register-based study among 1.2 million Finnish employees. Occup Environ Med 2018 Apr;75(4):296-302. https://doi.org/10.1136/ oemed-2017-104571.

20. Mechergui N, Ben Ali R, Faten B, Ben Khadra H, Ben Yahmed Y, Ladhari N. [Evaluation of psychosocial constraints among grocery stores workers in Tunisia]. Sante Publique 2019 May;31(3):443-50. https://doi.org/10.3917/ spub.193.0443.

21. Forcier L, Lapointe C, Lortie M, Buckle P, Kuorinka I, Lemaire $\mathrm{J}$ et al. Supermarket workers: their work and their health, particularly their self-reported musculoskeletal problems and compensable injuries. Work 2008;30(4):493510.

22. Harknett K, Schneider D, Wolfe R. Losing sleep over work scheduling? The relationship between work schedules and sleep quality for service sector workers. SSM Popul Health 2020 Oct;12:100681. https://doi.org/10.1016/j. ssmph.2020.100681.
23. Ropponen A, Koskinen A, Puttonen S, Härmä M. A casecrossover study of age group differences in objective working-hour characteristics and short sickness absence. J Nurs Manag 2020 May;28(4):787-96. https://doi. org/10.1111/jonm.12992.

24. Helgadóttir B, Svedberg P, Mather L, Lindfors P, Bergström G, Blom V. The association between parttime and temporary employment and sickness absence: a prospective Swedish twin study. Eur J Public Health 2019 Feb;29(1):147-53. https://doi.org/10.1093/eurpub/cky145.

25. Härmä M, Ropponen A, Hakola T, Koskinen A, Vanttola $\mathrm{P}$, Puttonen $\mathrm{S}$ et al. Developing register-based measures for assessment of working time patterns for epidemiologic studies. Scand J Work Environ Health 2015 May;41(3):268 79. https://doi.org/10.5271/sjweh.3492.

26. Härmä M, Sallinen M, Ranta R, Mutanen P, Müller K. The effect of an irregular shift system on sleepiness at work in train drivers and railway traffic controllers. J Sleep Res 2002 Jun;11(2):141-51. https://doi.org/10.1046/j.13652869.2002.00294.x.

27. Härmä M, Hakola T, Karhula K, Puttonen S, Ropponen A, Sallinen M. Työaikojen kuormittavuuden arviointi jaksotyössä [Evaluation of working hour loading in irregular shift work]: Finnish Institute of Occupational Health; 2021. Available from: https://www.ttl.fi/tyontekija/ tyoaika/tyoaikojen-kuormittavuuden-arviointi/tyoaikojenkuormittavuuden-arviointi-jaksotyossa.

28. Hakola T, Paukkonen M, Pohjonen T. Less quick returns-greater well-being. Ind Health 2010;48(4):390-4. https:// doi.org/10.2486/indhealth.MSSW-02.

29. Vedaa Ø, Harris A, Bjorvatn B, Waage S, Sivertsen B, Tucker $\mathrm{P}$ et al. Systematic review of the relationship between quick returns in rotating shift work and healthrelated outcomes. Ergonomics 2016;59(1):1-14. https://doi. org/10.1080/00140139.2015.1052020.

30. Catano VM, Bissonnette AB. Examining paid sickness absence by shift workers. Occup Med (Lond) 2014 Jun;64(4):287-93. https://doi.org/10.1093/occmed/kqu010.

31. Boudreau P, Dumont GA, Boivin DB. Circadian adaptation to night shift work influences sleep, performance, mood and the autonomic modulation of the heart. PLoS One 2013 Jul;8(7):e70813. https://doi.org/10.1371/journal. pone. 0070813 .

32. Reynolds AC, Bucks RS, Paterson JL, Ferguson SA, Mori TA, McArdle $\mathrm{N}$ et al. Working (longer than) 9 to 5: are there cardiometabolic health risks for young Australian workers who report longer than 38-h working weeks? Int Arch Occup Environ Health 2018 May;91(4):403-12. https://doi. org/10.1007/s00420-018-1289-4.

Received for publication: 23 November 2020 